\title{
Evaluation of the Social Determinants of Health in Communities across the South-Eastern Region of Nigeria
}

\author{
(D) Ngozi Joe-Ikechebelu, ${ }^{1}$ (D) Chidiebere Donatus Ignatius Osuorah, ${ }^{2}$ (1) Basil E Nwankwo, ${ }^{1}$ \\ (D) Williams Ngene, ${ }^{1}$ (D) Ezinne I Nwaneli ${ }^{3}$ \\ ${ }^{1}$ Department of Community Medicine/Primary health Care, Chukwuemeka Odimegwu Ojukwu University Faculty \\ of Medicine, Amaku-Awka, Anambra State, Nigeria \\ ${ }^{2}$ Child survival unit, Medical Research Council UK, The Gambia Unit, Gambia \\ ${ }^{3}$ Department of Paediatrics, Faculty of Medicine, Nnamdi Azikiwe University, Nnewi Campus, Anambra State, Nigeria
}

\section{ABSTRACT}

Objectives: Apart from lifestyles and genetic make-ups, a wide range of social, economic and environmental factors may affect personal and population health. Attaining sustainable health for all requires frequent evaluation and tackling these socio-economic and environmental factors.

Methods: This cross-sectional study aimed to evaluate the existence of the World Health Organization's (WHO) recognized social determinants health (SDH) in communities across south-east Nigeria. This study recruited 214 leaders in the state ministry of health who were stakeholders in the commission on SDH that attended a conference in Onitsha. Participants were enrolled using a purposive sampling method. Data on parameters of $\mathrm{SDH}$ in the communities were obtained on a scale of I to 5 using self-administered WHO-validated questionnaires for SDH.

Results: The existence of SDH in communities across the South-Eastern region in Nigeria is poor. Only 9.5$13.0 \%$ and $4.2-7.2 \%$ of the respondents respectively reported with high and very high certainty the existence of the parameters of SDH in their respective communities. Employment/job skills centers, police and security, legal aids, insurance policies and substance abuse help centers were the SDH parameters reported commonly as non-existent in most communities. The majority of the respondents reported education 88 (14.1\%), employment organizations $58(9.3 \%)$, healthcare $52(8.3 \%)$ and transportation $44(7.1 \%)$ as the health determinant with the strongest presence and greatest impact on lives of community residents, while access to mental health 24 (3.8\%), substance abuse treatment 20 (3.2\%), personal space $19(3.0 \%)$, insurance $22(3.5 \%)$ and parks $18(2.9 \%)$ for relaxation and leisure were reported as parameters with the weakest presence and least impact on health of community residents.

Conclusion: Continued assessment of the SDH in addition to the evaluation of its effects on personal and population health is imperative to deliver equitable healthcare and enhance the quality of life across communities in Nigeria.

Received Date: 06.05.2019

Accepted Date: 11.06.2019

Published online: 01.04 .2020

(C) Copyright 2020 by Anatolian Journal of Family Medicine -

Available online at www.anatoljfm.org

OPEN ACCESS

Keywords: Health, social, determinants, Nigeria

\section{INTRODUCTION}

The social determinants of health (SDH) are the conditions in which people are born, grow, live, work and age, and these conditions are shaped by the distribution of money, power and resources at global, national and local levels. ${ }^{[1]}$ Nigeria's health indicators are one of the worst in Africa despite its fast-growing population. ${ }^{[2]}$ Socioeconomic factors contribute significantly 
to dragging down the health of the country. Most notable of such factors influencing health in Nigeria is education. The probability of death among children born to illiterate mothers is twice higher than children born to literate mothers. ${ }^{[3]}$ Also, illiteracy has been found to be directly related to poverty, malnutrition, ill-health and high infant and child mortality. ${ }^{[3]}$ According to political economy of health, people considered to have low economic worth in the society would have unequal access to health care services and delivery. ${ }^{[4]}$ Household spending is affected by economic condition of a country. ${ }^{[5]}$ The National Bureau of Statistics of Nigeria reported a steady decrease in Gross Domestic Product (GDP) in 2015 . The GDP declined by $0.36 \%$ in Q1 and by $-2.06 \%$ in Q2. ${ }^{[6]}$ With the poor economic condition of the country, household spending is expected to decrease. Since more than half of Nigeria's population lives below the poverty line, this may negatively affect the health of the nation. ${ }^{[7]}$ Nnoyelu et al. observed that in Southeast Nigeria, the use of health facilities was more developed in high-income groups compared to the low- and medium-income counterparts, and poverty ranked highest among other factors that influence the use of health facilities in Southeast Nigeria. ${ }^{[8]}$ Health services are not only limited in number but are very costly, too. Gender inequality is often encountered in the country where it is traditionally believed that a fair share of the family's resources should be given to the male child. This includes but not limited education, nutrition and family inheritance. Hence, the females are disadvantaged, and since the mothers are traditionally the major caregiver of a child, the more uneducated and malnourished she is, the higher the likelihood of poor health in her child. Furthermore, there is a general view among South-easterners that the government plays an important role in the current health situation in the region through poorly functioning economic empowerment programs, low health budgets and skewed or inequitable distribution of health facilities to the disadvantage of rural areas and difficult terrains. ${ }^{[8]}$ It was given the poor health indices in the country that this study sought to identify the SDH of health in the Southeast region of the country.

\section{METHOD}

\section{Study Area}

This study was conducted in Onitsha, the largest city in Anambra state. The city is known for its commercial activities and is home to the largest open market in the westAfrica region. Anambra state is one of the five states in the Southeast region of Nigeria, with others being Enugu, Abia, Imo, and Ebonyi state. The economy of the South-eastern states are dependent mainly on national oil revenue and commerce. The region has a total land area of approximate- ly $40.000 \mathrm{~km}^{2}$ and 22 million residents according to the 2016 estimate by the National Population Commission of Nigeria. ${ }^{[9]}$ The population density in the region varies from 140 to 390 inhabitants per square kilometer. ${ }^{[10]}$ Most of the inhabitants in the region are Igbo by tribe, and Christianity is the dominant religion. The minimum monthly income in all participating states is similar to the national average of $\# 18.000$ (110 US\$). ${ }^{[11]}$ The literacy rate varies within and between the various states within the region with an average of $95.4 \%$ and $94.3 \%$ for female and male between the ages of 15-24 years, which is higher than the national average of $65 \%$ (59.3\% for females and $70.9 \%$ for males). ${ }^{[12]}$ The average fertility rate and neonatal mortality rate in the Southeast region is like the national average of 4.5 births per woman and 40 per 1.000 live births respectively. ${ }^{[1]}$

\section{Study Subject and Sampling Technique}

This is a cross-sectional descriptive study. This study was conducted on state representatives attending the June $30^{\text {th }}, 2017$ conference of the commission on SDH organized by the World Health Organization (WHO) in Onitsha. The attendees to the conference came from south-eastern states which includes Anambra, Enugu, Ebonyi, Imo and Abia states. Other states represented in the conference included Lagos, Ondo, Edo and Delta. Representatives that are not from the south-eastern states were excluded from the study. The conference attendees are stakeholders in the Commission of Social Determinants of Health (CSDH) in their respective states. The $\mathrm{CSDH}$ was established by WHO in March 2005 to support countries and global health partners in addressing the social factors leading to ill-health and health inequities. The Commission aims to draw the attention of governments and society to the SDH and in providing better social conditions for health, particularly among the most vulnerable people. ${ }^{[13]}$ These the commission believes will help improve daily living conditions of the populace, tackle the inequitable distribution of power, money, and resources and help measure problems in communities and assess their impacts on the lives of community members. ${ }^{[13]}$

The contingency of each states representatives to this year's conference varied from 10 to 100 . The minimum number of participants enrolled in this study was calculated using the Cochran formula for calculation of sample size which is based on a confidence interval of $95 \%$ equivalent to a confidence coefficient of 1.96 , south-east to national population ratio of $11.4 \%$ (i.e., $21,955,419$ of the national population of $193,392,517)$ and a non-response rate of $20 \%$. This gave a minimum sample size of 186 . Respondents from each participating state were selected using purpo- 
sive sampling method. A list of all the participants from the South-eastern states was compiled from the attendance register. Attendees were approached and participants that consented to participate in this study were consecutively enrolled. This process was done separately for all prospective participants representing their various states.

\section{Measures}

After obtaining verbal informed consent, trained research assistants interviewed the study participants regarding the elements of health determinants in their respective communities. Information on determinants of health was collected using the WHO validated questionnaire for SDH. Data were obtained from the following areas of health determinants: i) Healthcare needs; ii) Educational needs; iii) Housing needs; iv) Nutritional needs; v) Mental health needs; vi) Security needs; vii) Substance abuse prevention and rehabilitation needs; viii) Transportation needs; ix) Language needs; $x$ ) Employment needs and $x i)$ other determinants of health not included in these broad categories. The 5-point Likert scale rating system was used to assess participants' opinions on these parameters of health determinants where appropriate.

\section{Ethical Clearance and Consent to Participate in this Study}

Ethical clearance was obtained from the Ethical Committee of the Chukwuemeka Odumegwu Ojukwu University Teaching Hospital before data collection with the reference number of COOUTH/CMAC/ETH.C/VOL.1/0063 in April, 2017. In addition to this, verbal informed consent was obtained from every participant before enrollment. Participation in this study was entirely voluntary. Participants were informed that withdrawal at any stage of this study was guaranteed for them without any adverse effect. No identifier was associated with the data collected. All information was handled with strict confidentiality.

\section{Data Cleaning and Analysis}

A quality control check was carried out by researchers after enrollment. Where there are errors detected, the interviewers were asked to clarify them accordingly with the participants. Participants with grossly missing data were excluded from the analysis. Microsoft excel 2007 was used to input the raw data collected. Results were presented in percentages and charts where appropriate. Statistical significance was set at $p$-value $<0.05$.

\section{RESULTS}

\section{Characteristics of Respondents}

Two hundred and thirty women were enrolled for this sur- vey with a response rate of $100 \%$. Sixteen had grossly incomplete data and were excluded from the analysis. Two hundred and fourteen respondents were included in the analysis. Sixty six (30.8\%) were from Anambra state while the remainders were in almost equal proportion from other participating states. Approximately 96 (44.9\%) had tertiary education while 61 (28.5\%) attended post-secondary school institutions that are short of university-level education. Fifty seven (26.6\%) respondents chose not to state their highest educational attainment. The monthly income of respondents is shown in Table 1.

\section{Availability of SDH in Communities across South-east Nigeria}

Table 2 shows the respondents perceived state of the various components of health determinants in their communities. The majority of the respondents, $41.7-49.5 \%$, reported with some measure of certainty the availability of the assessed parameters of health determinants in their communities. Only approximately $9.6-13.0 \%$ of the respondents reported with high confidence the existence of these parameters, while approximately 4.2-7.2\% reported with very high confidence level existence of the assessed health determinants. This report showed a consistent response pattern across all determinants of health assessed

\begin{tabular}{|c|c|c|}
\hline Characteristics & $\begin{array}{c}\text { Frequency } \\
\text { (n) }\end{array}$ & $\begin{array}{c}\text { Percentages } \\
(\%)\end{array}$ \\
\hline \multicolumn{3}{|c|}{ Monthly income (in Naira) $(n=214)$} \\
\hline$<10000$ & 50 & 23.4 \\
\hline $10-29$ kף & 20 & 9.3 \\
\hline $30 k-39 k$ & 25 & 11.7 \\
\hline $50 k-99 k$ & 18 & 8.4 \\
\hline$>100 k$ & 11 & 5.1 \\
\hline Prefer not to answer & 90 & 42.1 \\
\hline \multicolumn{3}{|c|}{ Tertiary education $(n=214)$} \\
\hline No & 61 & 28.5 \\
\hline Yes & 96 & 44.9 \\
\hline Not stated & 57 & 26.6 \\
\hline \multicolumn{3}{|c|}{ State representatives in survey $(n=214)$} \\
\hline Anambra state & 66 & 30.8 \\
\hline Imo & 40 & 18.7 \\
\hline Enugu & 42 & 19.6 \\
\hline Ebonyi & 32 & 15.0 \\
\hline Abia & 34 & 15.9 \\
\hline
\end{tabular}


Table 2. The opinions of the surveyed women on the availability of the determinants of the health in their various communities

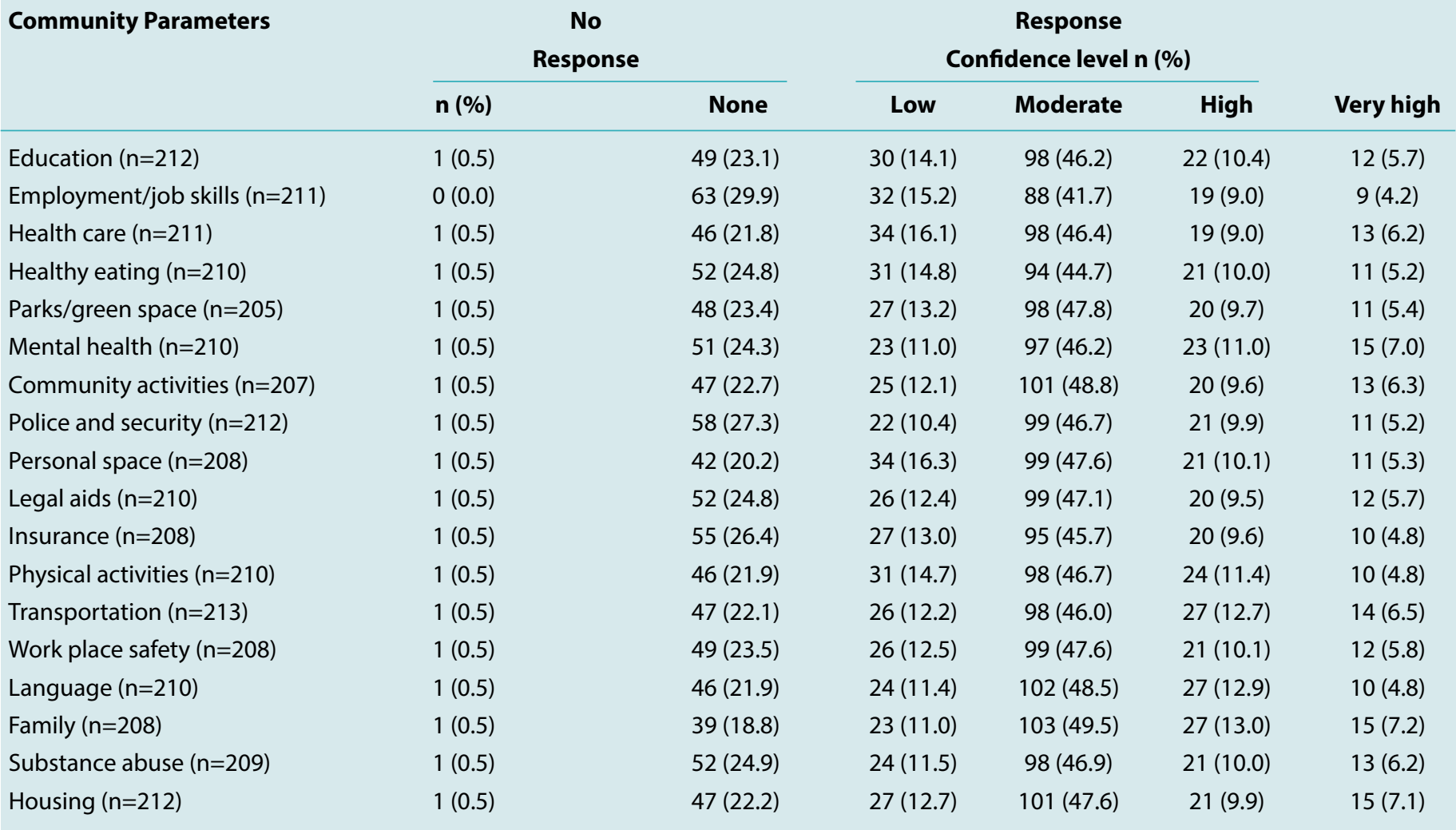

in this study. Table 3 shows the various SDH and their perceived impacts on community residents. The majority of the respondents reported education (14.1\%) as the health determinant with the strongest greatest impact on the lives of community residents. This was followed by employment organizations (9.3\%), healthcare (8.3\%) and transportation (7.1\%). On the other end of the spectrum, access to mental health (3.8\%), substance abuse treatment (3.2\%), personal space (3.0\%), insurance (3.5\%) and parks (2.9\%) for relaxation and leisure were reported as health determinant parameters with the least impact on community residents. Language skills, public legal assistance and job skills acquisition were reported by respondents to have little or no impact on the daily lives of community residents. Furthermore, of the SDH present in most communities, respondents believe that healthcare delivery (17.9\%), employment opportunities (9.2\%) and affordable housing (10.8\%) were mostly inadequate in their community and needed urgent enhancements to improve quality of life of residents in these communities. Table 4 shows the components of the various health determinants respondents believe are most needed in their various communities. Under healthcare, primary healthcare (27.4\%), eye care $(18.5 \%)$ and other specialty care (19.4\%) were regarded as the most important elements of health services needed by community residents. Likewise, under nutritional needs, access to affordable healthy foods was clearly the most important (59.7\%). Mental health prevention programs $(32.5 \%)$ and the presence of mental health professionals and/or institutions (31.6\%) were regarded as the most needed facilities needed for adequate mental health of communities. Concerning educational needs, child development (24.3\%), youth development (14.3\%), quality education (14.9\%), adult education (10.9\%) and life skill acquisition (10.0\%) were top necessities while senior housing (37.2\%), affordable housing 46 (19.2\%) and access to housing loans (17.2\%) were perceived priority areas for community members with regards to housing and living. Other priority areas of the various health determinants listed by respondents are shown in Table 4.

\section{DISCUSSION}

Our study sought to highlight the existence of some WHO recognized SDH in communities in South-east Nigeria. It was noted from the findings of this study that the presence of these health determinants was non-existent in most evaluated communities and where available, were poorly implemented. Less than ten percent of all respon- 
Table 3. Respondents perceived impacts of the various health determinants on the lives of the community residents

\begin{tabular}{|c|c|c|c|c|}
\hline \multirow[t]{2}{*}{ Health Determinants } & \multicolumn{4}{|c|}{$\begin{array}{c}\text { Impacts on } \\
\text { Community Residents }\end{array}$} \\
\hline & Strong & (\%) & Weak & (\%) \\
\hline Education & 88 & 14.1 & 45 & 4.6 \\
\hline Employment & 58 & 9.3 & 90 & 9.2 \\
\hline Healthcare & 52 & 8.3 & 174 & 17.9 \\
\hline Healthy eating & 39 & 6.3 & 66 & 6.8 \\
\hline Parks green space & 18 & 2.9 & 15 & 1.5 \\
\hline Community safety & 53 & 8.5 & 26 & 2.7 \\
\hline Community activity & 36 & 5.8 & 33 & 3.4 \\
\hline Police and security & 42 & 6.7 & 36 & 3.7 \\
\hline Personal space & 19 & 3.0 & 47 & 4.8 \\
\hline Insurance policy & 22 & 3.5 & 27 & 2.8 \\
\hline Transportation & 44 & 7.1 & 57 & 5.9 \\
\hline Workplace safety & 28 & 4.5 & 18 & 1.9 \\
\hline Language & 21 & 3.4 & 34 & 3.5 \\
\hline Family & 29 & 4.6 & 18 & 1.9 \\
\hline Mental health treatment access & 24 & 3.8 & 34 & 3.5 \\
\hline Substance abuse treatment access & s 20 & 3.2 & 30 & 3.1 \\
\hline Affordable housing options & 31 & 5.0 & 105 & 10.8 \\
\hline Language skills & 0 & 0.0 & 25 & 2.6 \\
\hline Legal aid & 0 & 0.0 & 41 & 4.2 \\
\hline Job skills & 0 & 0.0 & 49 & 5.2 \\
\hline Total & 624 & 100 & 970 & 100 \\
\hline
\end{tabular}

dents indicated very high confidence in the existence of all twenty SDH in their respective communities. According to the $\mathrm{WHO}$, these $\mathrm{SDH}$ are important because they combine to affect the health of individuals and communities. ${ }^{[14]}$ It further reports that the health state of a population, is determined by their circumstances and environment. ${ }^{[14]}$ In other words, aside availability of healthcare services, the SDH are important as they directly impact on how people interact with available health resources in their communities.

A study conducted in four countries in Africa showed that gender inequities, such as polygyny (husband having other wives), justifying wife-beating (stressful relationships), age at first marriage (less than 19 years), and educational inequality (being less educated than partner) were differentially and significantly associated with the different measures of poor access to reproduc-tive health care within these four countries. ${ }^{[15]}$ Other social factors, such as education, transportation, secure job and housing, have also been documented as factors that determine the health state of community members. ${ }^{[16-18]}$ Based on the findings of the referenced studies, we can infer that the reasonable availability of healthcare service in a community does not translate to being healthy. To a large extent, factors, such as where we live, the state of our environment, our income education level, and our relationships with friends and family, all have considerable impacts on health. ${ }^{[14]}$

Our study also showed that about a third of respondents indicated the non-existence of employment/job skills centers, police and security, legal aids, insurance policies and substance abuse prevention and treatment programs in their various communities. These factors are without a doubt, necessary for holistic personal and population health, defined by the WHO, "as a state of complete physical, mental and social well-being and not merely the absence of disease or infirmity". ${ }^{19]}$ Huber et al. in their own definition described health as the ability to adapt and manage physical, mental and social challenges throughout life. ${ }^{[20]}$ Consequentially, as suggested by the WHO, a population that lacks amenities, such as security, insurance, employment and/or job acquisition center, legal services aid and other socio-economic health determinants, cannot be said to be in a state of mental and social wellbeing even when there is presence healthcare services facilities in such communities. For instance, a prospective study on 300 men reported that unemployed men made significantly more visits to their physicians, took more medications, and spent more days in bed sick than employed individuals even though the number of diagnoses in the two groups was similar. ${ }^{[21]}$ Similarly, a large scale study in Canada noted that unemployment is significantly correlated to higher morbidity and mortality rates among men and women. ${ }^{[22]}$ It is, therefore, important that health agencies, in collaboration with state and local government authorities, advocate assiduously for the provision of these vital health determinants in communities where they are non-existent.

There is a dearth of studies assessing the SDH in Nigeria. This study is one of the very few studies that attempt to evaluate these factors. However, due to logistics, we were unable to visit these communities to physically assess the availability and/or non-availability of these health determinants. This limitation we hope to address in the next phase of this study by involving field workers, policymakers and community members for an on-the-ground assessment that will give a clearer picture of health determinants in communities in South-east Nigeria. 
Table 4. Essential elements of the health determinants assessed for the improved quality of life community residents

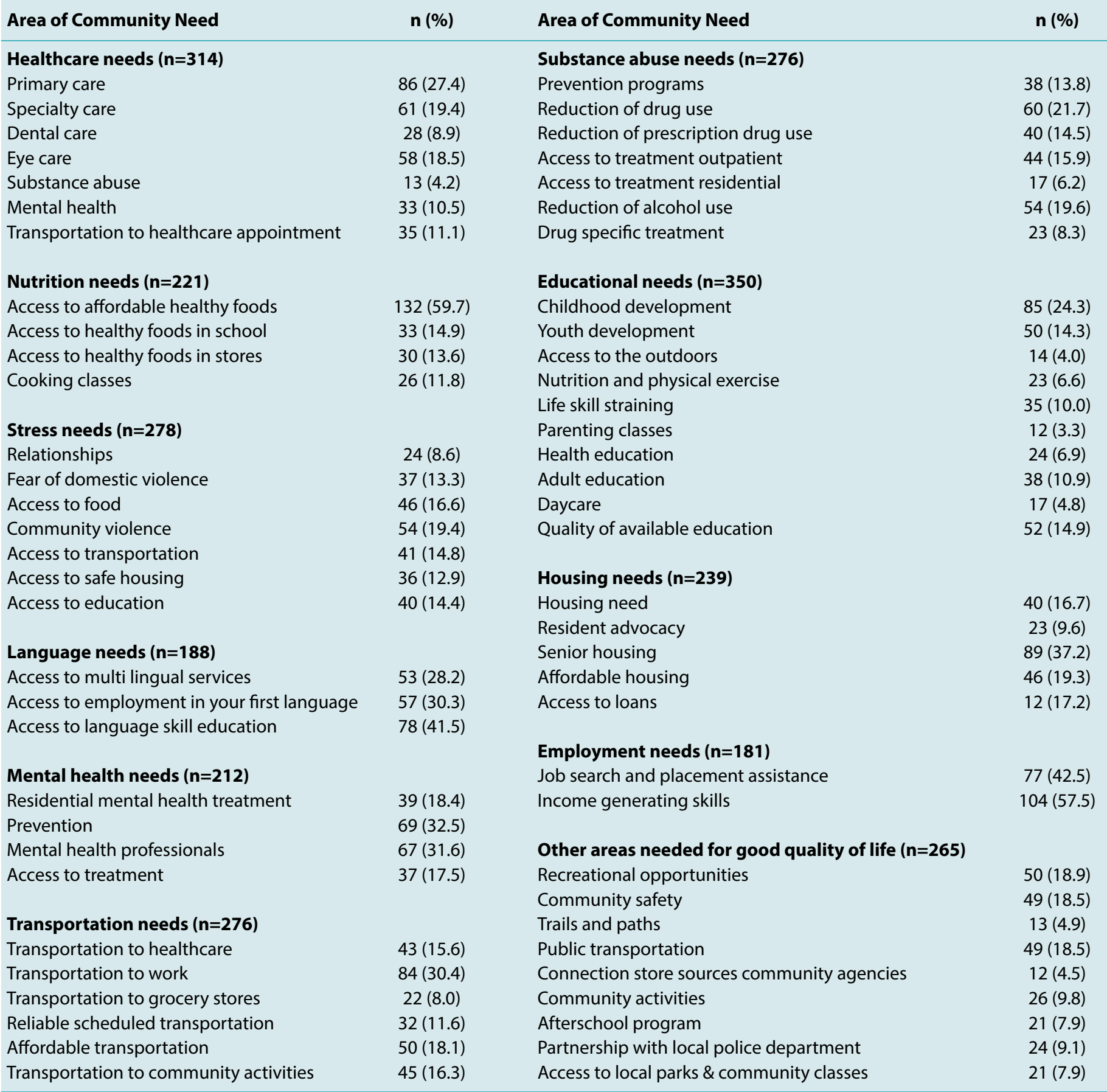

\section{Acknowledgements}

The authors would like to thank all the study participants for their time and effort in completing this study questionnaire and the management of the Chukwuemeka Odimegwu Ojukwu University teaching hospital for the logistic support during this study.

\section{Disclosures}

Peer-review: Externally peer-reviewed.

Conflict of Interest: None declared.
Ethics Committee Approval: The study was approved by the Local Ethical Committee of the Chukwuemeka Odumegwu Ojukwu University Teaching Hospital, Anambra state.

Authorship Contributions: Concept - N.J.I.; Design - N.J.I.; Supervision - B.N., W.N.; Materials - N.J.I.; Data collection \&/or processing - C.D.I.O.; Analysis and/or interpretation - C.D.I.O.; Literature search - E.I.N.; Writing - C.D.I.O., N.J.I., E.I.N.; Critical review - N.J.I., C.D.I.O., B.E.N., W.N., E.I.N. 


\section{REFERENCES}

1. World Health Organization. Social determinants of health. Available at https://www.who.int/social_determinants/sdh_ definition/en/ Accessed April 1, 2019.

2. United States Agency for International Development. Gobal Health. Available at https://www.usaid.gov/nigeria/globalhealth. Accessed April 1, 2019.

3. World Health Organization. Social Determinants of HealthNigerian Perspective. The Regional Consultation of the Commission on Social Determinants of Health. Brazzaville, Congo. 2005. Available at https://www.who.int/social_determinants/ country_action/NIGERIA\%20Dr \%20ADETUNJI\%20Labiran. pdf. Assessed April 1, 2019.

4. Gusau GA. Political Economy of Medical Education in Nigeria. (dissertation). Nigeria: Jos University Department of Sociology. 1992.

5. Gittins $P$, Luke S. Impact of recession on household spending. Office for National Statistics. 2012. Available at www.ons.gov. uk>ons>dcp1717. Accessed April 1, 2019.

6. The Federal Republic of Nigeria National Bureau of Statistics. Nigerian Gross Domestic Product Report. Quarter two. 2016. Available at www.nigerianstat.gov.ng/ elibrary / page $=24$ offset $=230$. Accessed April 1, 2019.

7. Alaba AO, Alaba OB. Malaria in Children: Implication for the Productivity of Female Caregivers in Nigeria. In: Ozo-Eson, Peter I, Evbuomwan G (editors). Human resource development in Africa: Selected papers for the 2002 Annual Conference of the Nigerian Economic Society. Ibadan Secretariat, Department of Economics, University of Ibadan. 2003:395-413.

8. Nnonyelu N, Nwankwo IU. Social Determinants of Differential Access to Health services across Five States of Southeast Nigeria. Euro Sci J 2014;3:286-96.

9. National Population Commission and National Bureau of Statistics Estimates 2006-2016. Available and assessed on 26/02/2019 from https://africacheck.org/wp-content/uploads/2017/02/Population-Forecasts.pdf.

10. Wikipedia article on Igboland. Available and assessed on 26/02/2019 from https://en.wikipedia.org/wiki/lgboland and assessed on 26/02/2019.
11. Nigerian Population Commission. State and local government demographic profile: 1991-2010, Abuja.

12. Federal ministry of Education. Literacy rate in Nigeria by states. Educational Planning Research and Development 2017. Available from http://education.gov.ng/tertiary-education/. Assessed April 5, 2019.

13. World Health Organization. Commission on Social Determinants of Health, 2005-2008. Available from https://www.who. int/social_determinants/thecommission/en/. Assessed April 5, 2019.

14. World Health Organization 2019. Social determinants of health, Health Impact Assessment (HIA) 2005-2008. Available from https://www.who.int/hia/evidence/doh/en/. Assessed April 5, 2019.

15. Namasivayam A, Osuorah DC, Syed R, Antai D. The role of gender inequities in women's access to reproductive health care: a population-level study of Namibia, Kenya, Nepal, and India. Int J Womens Health 2012;4:35c-64.

16. Chiavarini M, Lanari D, Minelli L, Salmasi L. Socio-demographic determinants and access to prenatal care in Italy. BMC Health Serv Res 2014;14:174. [CrossRef]

17. Ekwochi U, Ndu IK, Osuorah CD, Onah KS, Obuoha E, Odetunde OI, et al. Delays in healthcare delivery to sick neonates in Enugu South-East Nigeria: an analysis of causes and effects. J Public Health (Oxf) 2016;38(2):e171-7. [CrossRef]

18. Thomson H, Petticrew M, Morrison D. Health effects of housing improvement: systematic review of intervention studies. BMJ 2001;323(7306):187-90. [CrossRef]

19. World Health Organization. Constitution of the World Health Organization - Basic Documents. 45th ed. Supplement, October 2006. Available from http://apps.who.int/gb/bd/. Assessed April5, 2019.

20. Huber M, Knottnerus JA, Green L, van der Horst $H$, Jadad $A R$, Kromhout D, et al. "How should we define health?". BMJ 2011;343:d4163. [CrossRef]

21. Linn MW, Sandifer R, Stein S. Effects of unemployment on mental and physical health. Am J Public Health 1985;75(5):502-6.

22. Jin RL, Shah CP, Svoboda TJ. The Impact of Unemployment on Health: A Review of the Evidence. CMAJ 1995;153(5):529-40. 